\title{
The role of wild vegetable species in household food security in maize based subsistence cropping systems
}

\author{
S. Mavengahama $\cdot$ M. McLachlan $\cdot$ W. de Clercq
}

Received: 2 November 2012 / Accepted: 18 January 2013 /Published online: 6 February 2013

(C) The Author(s) 2013. This article is published with open access at Springerlink.com

\begin{abstract}
Wild vegetables (WV) are an important source of food in the maize based subsistence farming sector of rural South Africa. Their main role is as relish as they are used as an accompaniment for staple cereal based diets. They are generally reported to be rich in micronutrients. Although they may be consumed in small quantities, they influence the intake of cereal staples, manage hunger and play a central role in household food security for the poorer rural groups. Mixing several WV species in one meal contributes to dietary diversity in terms of more vegetable types as well as in terms of choice of relish. For some very poor families WV are substitutes for some food crops. The seasonal occurrence of these vegetables leaves many families without a food source during the off-season. Wild vegetables increase agro-biodiversity at the household level. This agrobiodiversity helps in buffering against the accumulation and multiplication of pests and diseases and provides important cover for the soil. Further research on agronomic, social and economic dimensions is required to understand
\end{abstract}

This paper is part of a thesis to be submitted to the Department of Soil Science, Faculty of AgriSciences, Stellenbosch University, South Africa.

S. Mavengahama $\cdot$ W. de Clercq

Department of Soil Science, Faculty of AgriSciences,

Stellenbosch University, Private Bag X1,

Matieland 7602, South Africa

M. McLachlan

Department of Human Nutrition, Faculty of Medicine and Health

Sciences, Stellenbosch University, Private Bag 19063,

Tygerberg 7505, South Africa

Present Address:

S. Mavengahama $(\square)$

Department of Agriculture, Faculty of Science and Agriculture,

University of Zululand, Private Bag X1001,

KwaDlangezwa 3886, South Africa

e-mail: sydmavengahama@yahoo.co.uk the roles of WV in subsistence farming systems in South Africa.

Keywords Household food security · Wild vegetables ·

Maize based cropping systems · Subsistence farming system

\section{Introduction}

Wild vegetables (WV) are an important source of food, mainly in the rural parts of South Africa (Jansen van Rensburg et al. 2007; Modi et al. 2006; Vorster et al. 2007; Vorster et al. 2008; Shackleton 2003). This is especially so in the maize (Zea mays L.) based subsistence farming sector where they are eaten as relish to accompany phutu which is prepared from maize meal. The emphasis on maize based cropping systems is premised on the knowledge that the main staple, maize meal porridge, (phutu) invariably requires relish to complement it and that among the most impoverished groups of the rural population WV assume the role of main relish. Some of the commonly occurring and important WV in selected regions of South Africa are presented in Table 1. A comprehensive discussion on the occurrence and distribution of other and lesser utilised WV in different parts of South Africa can be found in Jansen van Rensburg et al. 2007; Maanda and Bhat 2010; Steyn et al. 2001 and Odhav et al. 2007.

The importance of WV has, until recently, been largely unrecognised and unacknowledged by agricultural policy makers (Rubaihayo 2002; Shackleton 2003), researchers and nutritionists alike. The main valuable attribute of these WV plant species, about which many researchers are in agreement, is their high nutritional (micronutrient) content (e.g. Steyn et al. 2001; Nesamvuni et al. 2001; Odhav et al. 2007). The ability of any food to provide nutrients is one of the important components of food security. WV presently contribute to the alleviation of household food insecurity 
Table 1 Some commonly occurring vegetables in parts of KwaZulu-Natal and the Limpopo Provinces of South Africa

Adapted from Steyn et al. 2001; Odhav et al. 2007 and Lewu and Mavengahama 2010

${ }^{a}$ The seasonality is reported for Limpopo Province only. KwaZulu-Natal has both Mediterranean and tropical climates; therefore the occurrence of the wild vegetables varies greatly

\begin{tabular}{llll}
\hline Scientific name & \multicolumn{2}{l}{ Vernacular names in different regions } & \multirow{2}{*}{ Season $^{\text {a }}$} \\
\cline { 2 - 3 } & KwaZulu-Natal Province & Limpopo Province & \\
\hline Amaranthus hybridus & imbuya & vowa,thebe & all year \\
Amaranthus spinosus & imbuya & imbuya & summer \\
Bidens pilosa & uqadolo & mushidzhi & all year \\
Chenopodium album & imbilikicana & umbicani & spring \\
Cleome gynandra & - & murudi & all year \\
Cleome monophylla & isiwisa & - & - \\
Momordica foetida & intsungu & nngu & summer \\
Galinsoga perviflora & isishukeyana & - & - \\
Solanum nigrum & umsobo & umsobo muxe & summer \\
Corchorus olitorius & ligusha & - & - \\
Corchorus trilocularis & - & delele & summer/autumn \\
\hline
\end{tabular}

(Legwaila et al. 2011) but this contribution could be increased through the promotion of their consumption and their integration in the maize based cropping systems at household level in subsistence farming systems in South Africa in particular, and in smallholder cropping systems in general.

There have been many attempts to define the concept of food security. The FAO (2008) definition which says food security is "a situation that exists when all people, at all times, have physical, social, and economic access to sufficient, safe, and nutritious food that meets their dietary needs and food preferences for an active and healthy life" is widely used. Four key dimensions of food security have also been identified namely: food availability, food accessibility, food system stability and food utilization (FAO 2008).

Prior to the 1970s, food security mainly related to national food production and international trade (Devereux and Maxwell 2001; Maxwell and Smith, undated), but the concept has since been expanded to include households' and individuals' access to food. Generally, looking at food security from a wider (national/regional) viewpoint has the effect of masking or concealing the shortages or deprivation at household level. This is because commercial agriculture, which uses irrigation infrastructure, inputs such as fertilisers, pesticides, labour and appropriate farming knowledge, can lead to high yields and contribute to food security at national level. Several reports have indicated that South Africa is food secure at national level (e.g. Koch 2011; Altman et al. 2009) but there is variation on the reported status of household food security. Studies on household food security in South Africa use a range of indicators and measurement tools. Consequently, reported levels of food insecurity vary widely across studies. Household food insecurity levels ranging from 35 to $73 \%$ have been reported (Hendriks 2005). Jacobs (2009) estimated that roughly $85 \%$ of the population cannot afford to purchase a balanced diet providing sufficient energy. High levels of chronic malnutrition among infants and young children are further evidence that food insecurity is a significant problem at household level.

Food security goes beyond food availability and accessibility, it also includes whether the diet is balanced - that is, whether all the essential nutrients are available in their correct proportions (FAO 2008). We argue that if a household has enough maize to provide adequate phutu throughout the year but struggles to get relish most of the time, such a household cannot be regarded as food secure since the absence of relish means that the maize meal will not be palatable and therefore may not be eaten in sufficient quantities to give an adequate diet. Furthermore, foods from the wild such as indigenous vegetables, fruits, mushrooms and bush meat which contribute to the rural household food basket are usually not included in national foods baskets (Legwaila et al. 2011; Bharucha and Pretty 2010). Without a better understanding of these dimensions of food insecurity at household level, it is difficult to estimate total food insecurity and understand the causes of vulnerability to food insecurity among rural households.

\section{Problem statement}

There is a growing recognition that the present problems with food insecurity and poor nutrition need an integrated approach, which acknowledges the complex and integrated nature of rural poverty (Chambers 1990) so as to achieve synergies through the integration of various disciplines in mitigating the problem (see McLachlan and Garrett 2008). We posit in this paper, that the integration of WV cultivation in the subsistence farming sector in South Africa can contribute to the alleviation of household food insecurity. There is a growing body of literature from various parts of the world on the role of $\mathrm{WV}$ in household nutrition, mostly indicating that these species are important as a food source 
(Bharucha and Pretty 2010; Jansen van Rensburg et al. 2007; Modi et al. 2006; Vorster et al. 2007; Vorster et al. 2008; Shackleton 2003; Flyman and Afolayan 2006a; Legwaila et al. 2011). Maunder and Meaker (2007) have concluded that the combined efforts of nutritionists and agriculturalists are needed to promote and enhance the utilisation of WV as some of the crops consumed at household level. Similarly, in a study on the utilisation of these vegetables among the Vhavhenda people, Nesamvuni et al. (2001) encouraged health educators to promote the nutritional advantages of WV. There are knowledge gaps regarding the importance, abundance, and ease of cultivation of WV and even on the need to domesticate and cultivate them, yet not much empirical evidence is available to support or rebut these observations. During some of our research cohort meetings, some colleagues have argued that WV are widely and freely available and abundant and therefore there is no need to cultivate them. They argue that these vegetables are only needed in small quantities and the naturally occurring amounts should be adequate. Others have raised doubts as to the feasibility of completely domesticating these plant species and question whether they are actually important in household food security in terms of food bulk.

Some researchers have reported that rural people perceive the populations of WV to be in decline (Shackleton 2003; Vorster et al. 2008). Our own observations and experiences are that even for seemingly abundant wild species such as Amaranthus (pigweed) and Bidens pilosa (black jack), people do not indiscriminately consume all of the available varieties but select, depending on certain specific (un)desirable characteristics like leaf hairiness, astringency (bitterness) and leaf size (which influences ease and speed of gathering/harvesting). As a result, not all that is available is consumed. There is still need for researchers to closely interact with people so as to clearly understand people's perceptions and utilisation patterns at household level with respect to WV. It is also argued here that if these vegetables are mostly used in times of food shortage in the home, then there is also likely to be a shortage of other ingredients and other seasoning additives that make any relish tasty. As a result, both adults and children will come to associate these vegetables with poor taste, which might not be an inherent feature of the vegetables themselves, but a result of inadequate ingredients.

The goal of this paper is to critically review the role that WV play in household food security for those who rely on maize based subsistence cropping systems. It also highlights some of the generally agreed roles and the threats to $\mathrm{WV}$ in the literature. The following questions are explored.

1. What are the roles of WV in household food security in poor rural households?

2. What is the nutritional composition of $\mathrm{WV}$ and what factors contribute to the bioavailability of these nutrients?
3. What are the threats to WV utilisation?

\section{Methods used for literature search}

This paper is an outcome of a broader trans-disciplinary (Td) study, which uses different methods to generate information. Some of the knowledge was generated during discussions with colleagues during our regular Td meetings. For this particular critical review the literature was obtained from various sources. The search was limited to peerreviewed papers published in journals. A comprehensive search was conducted by subject, using the Google search engine, on the following search terms: "wild vegetables" or "wild vegetables in South Africa" or "indigenous vegetables" or "food security in South Africa" or "household food security in South Africa." Through an analysis of the content of returned entries, papers were selected based on their relevance to the subject of this review. The records were then analysed and those records that were journal publications were assessed further. Forty papers were considered relevant and included in the review.

\section{Roles of wild vegetables in subsistence farming systems}

They are an integral component of the main meal of the day

WV species integrated as part of the main diet have a role in the management of hunger and specifically micronutrient deficiencies. Their main role is as relish (Oniang'o et al. 2003), that is, they are used as complement for staple diets (such as phutu, pap, sadza or ugali), made mainly from maize meal and sometimes other cereals such as sorghum (Sorghum bicolor L. Moench) and pearl millet (Pennisetum typhoides). They are thus an integral component of the main meal of the day as usually they are the main relish with which the staple maize dish is eaten. They are usually prepared as the preferred relish on their own or as substitute for exotic vegetables in stews and soups in cases where meat and other vegetables cannot be afforded. However, where an alternative relish is available, they can be referred to as a supplement (Kepe 2008). Relish is an indispensable part of the African diet (Smith and Ezyaguirre 2007; Oniang'o et al. 2003) as the main staple cereal is not normally eaten in the absence of relish. Thus the presence of relish directly impacts on the consumption of the bulk of the main staple even though the relish is required and consumed in smaller proportions relative to the staple.

It is evident from the foregoing that WV play a significant role in food system stability at the household level. Food system instability is determined by the temporary or permanent loss of access to the resources needed to consume adequate 
food (FAO 2008). The temporal variability in the occurrence of $\mathrm{WV}$, due to their seasonal availability in response to the changes in seasons of the year, certainly causes instability in local rural food systems, especially among those vulnerable groups who depend totally on them for relish (see Modi et al. 2006; Vorster et al. 2007; Shackleton 2003; Lewu and Mavengahama 2010, 2011).

\section{Nutritional role}

One attribute of WV, about which there is general agreement among researchers, is their potential to combat 'hidden hunger' (Tisdale et al. 1990; Harvestplus 2011). This is especially important among low income earners and the rural population (Lewu and Mavengahama 2010) as the vegetables are not purchased. The nutritional composition of $\mathrm{WV}$ has been, and continues to be, characterised and they generally have been reported to be rich in micronutrients especially beta carotene, zinc, and iron, the principal nutrients whose absence from a diet results in 'hidden' hunger. Several studies conducted on indigenous vegetables have suggested that they generally have higher levels of various nutrients than the conventionally cultivated species (Flyman and Afolayan 2006b; Ndlovu and Afolayan 2008; Odhav et al. 2007; Steyn et al. 2001; Nesamvuni et al. 2001). Micronutrient malnutrition affects more than half of the world population, particularly in developing countries (WHO 2000). In 2000, the World Health Report identified iron, vitamin A, zinc and iodine deficiencies as the most serious health constraints worldwide (WHO 2000; Faber and Wenhold 2007). Besides nutritional benefits, it has been suggested that the utilisation of these vegetables represents significant savings of cash in the household (Shackleton 2003).

\section{Nutritional challenges of wild vegetables}

More research needs to be conducted on the ability of WV to contribute nutrients to the body. This is because research has suggested that nutrients from WV may not be bioavailable. The food security concept of food utilization goes beyond food use and includes how a person is able to absorb essential nutrients from the consumed food (FAO 2008) and includes the concept of bioavailability. The bioavailability of nutrients is influenced by the presence in a meal of substances that either promote or inhibit absorption of nutrients by the gut (Lonnerdal 2003; Gupta et al. 2006). These substances, which include phytate, oxalate and polyphenols are variously called anti-nutrients or anti-nutritional factors. They occur not only in WV but also in cultivated vegetables and fruits (oxalate), cereal and legume seeds (phytate) and beverages such as tea and coffee (polyphenols) (White and Broadly 2009). It is estimated that only about $25 \%$ and $5 \%$ of the zinc in cereals and legumes, respectively, is bioavailable.
The bioavailability of the nutrients in WV has not been widely characterised. WV (and other foods) may be rich in mineral nutrients but these nutrients may not be easily available (bio-availability) due to anti-nutritional substances such as phytate and tannins which bind zinc, calcium and iron. If $\mathrm{WV}$ are mixed with other foods in the diet their anti-nutrients could render the micronutrients from the staples unavailable. However, as noted earlier, antinutrients also occur in beverages like coffee and tea and have therefore been present in diets for a long time.

\section{Dietary diversity and cultural value}

The widely observed practice of mixing several WV species in one cooking vessel highlights their contribution to dietary diversity in terms of more vegetable types as well as in terms of choice of relish. Although most researchers have emphasized the superior nutritional composition of these species, this is not their only merit. There are other reasons behind the use of these species. It is not uncommon for the urban wealthy to be found visiting certain places where ethnic (traditional) foods are prepared, looking especially for these vegetables and other traditionally prepared meals (as alluded to by Kepe 2008). They provide variety to otherwise monotonous cereal based diets (see Michaelsen et al. 2009; Maholtra and Passi 2007). Providing different types of these $\mathrm{WV}$ can reduce this monotony by adding different tastes and colours to diets.

Although edible indigenous plant species have been utilised as food for centuries (Vorster et al. 2008; Adebooye and Opabode 2004) current research has indicated that the use of WV in South Africa is in decline (Steyn et al. 2001; Modi et al. 2006). Flyman and Afolayan (2006b) have suggested that reliance on introduced exotic vegetables was the primary reason for the decline in Southern Africa. Lack of knowledge about nutritional composition, cooking methods and ways of preservation have also been suggested as reasons for low use of WV (Flyman and Afolayan 2006b). Mnzava (1997) referred to 'strongly localized importance' as also reducing utilisation. This localized importance has also been alluded to by Jansen van Rensburg et al. (2007) who reported that although Corchorus olitorius (Jews mallow/wild okra) occurs in Limpopo, KwaZuluNatal and Eastern Cape, it is only consumed in Limpopo because people in the other provinces do not like its sliminess. Rubaihayo (2002) and Vorster et al. (2008) have suggested that the indigenous knowledge base of these vegetables has been eroded due to environmental and socio-cultural changes brought about by migration of labour, increased urbanisation and the promotion of cash crop farming instead of subsistence farming. Bharucha and Pretty (2010) have noted that food security is presently dependent on only a narrow variety of cultivated species. 
Security against food shortages

Although they carry a 'food for the poor' and 'famine food' tag for some groups, the fact remains that WV are indeed an important last resort during famine. For some rural groups mired in the deprivation trap and perpetual poverty WV are substitutes for food crops (Kepe 2008). There are some groups in society who would not ordinarily eat these vegetables under circumstances of adequate food availability but would consume them under difficult conditions of droughts and famines. It is possible that for some people who are in poverty these foods become such a part of their diets that even when circumstances change for the better, the attachment to these foods does not go away. Thus a drought induced famine would have social-cultural effects on wild vegetable use as suggested by Bharucha and Pretty (2010).

Farm level agro-biodiversity and resilient local food systems

WV increase agro-biodiversity at the household level. This agro-biodiversity helps in buffering against the accumulation and multiplication of pests and diseases; it also provides important cover for the soil at the edges of the fields or fault lines in the field which are prone to erosion - their roots together with other weeds hold the soil in place and reduce raindrop impact. This is especially true for the widely occurring species such as black jack (Bidens pilosa) and pigweed (Amaranthus hybridus). The hardiness of WV ensures that they thrive in both drought and flood times and as a result they are available during harsh environmental conditions when most cultivated crops would have failed. They are thus resilient and their increased utilisation and cultivation would introduce resilience into the food systems of most subsistence farmers (see Bradford 2010).

\section{Threats to wild vegetables}

The current manner of use of WV relies on harvesting without cultivation, a practice that may be regarded as exploitative and therefore unsustainable in view of increasing population density. It could lead to genetic erosion (see Flyman and Afolayan 2006a) and possible loss of biodiversity (Shackleton 2003; Bharucha and Pretty 2010). Decline in the wild population of some indigenous vegetables has already been reported (Shackleton 2003). Further, utilisation is also unsustainable in that the benefiting people have no control over availability as they do not cultivate these vegetables. Thus, availability is unpredictable and variable. An alternative to this utilisation approach is the integration of indigenous vegetables in cropping systems. This could result in increased agro-biodiversity. Increased genetic diversity has been shown to support food security as well as buffering against unfavourable environmental conditions, pests and diseases (Venter et al. 2007; Moore and Raymond 2006).
Kwapata and Maliro (1995) have suggested that the decline in wild vegetable use is due to chemical elimination as they are considered as weeds. This is especially true in Southern Africa where agricultural education in both commercial and communal areas is aimed at cash crop production. This type of farming promotes mono-cropping (or mono-culture) and emphasizes the eradication of any other plant species in the field as they are regarded as weeds. This attitude towards WV still prevails among researchers and extension workers who continue to advise farmers to remove them from their fields (Vorster et al. 2007; Shackleton 2003).

\section{Some research needs regarding wild vegetables}

The attitudes and perceptions of people towards WV are not yet fully understood. The willingness of people to formally adopt these vegetables as cultivated crops maybe influenced by perceptions, cultural beliefs, values and social stigmas attached to them. Do people view these plant species as important vegetables, or, as suggested by Shackelton et al. (2006), just as `safety nets' to be used when there is not enough food during droughts, famine or lack of money to purchase exotic vegetables? There is thus need for more in depth participatory studies on the indigenous knowledge systems about these species as well as on the current importance of these vegetables in the household economy. Studies on the nutritional composition of WV are required. The amounts of nutrients reported for the same species from different studies vary widely (Uusiku et al. 2010). The question then is what factors affect the nutritional composition of these vegetables? More controlled experiments on aspects such as effect of soil type, effect of fertiliser amount and type, and age of harvesting on the nutritional composition of WV need to be conducted. The bioavailability of micronutrients also needs to be determined for cooked vegetables as most of the available data are on raw samples (Uusiku et al. 2010). The abundance and diversity of these vegetables need to be determined. Diversity studies are especially important as a preliminary step in breeding of these species for desirable traits such as low anti-nutrients and low astringency, high micronutrient content as well as high yield of the edible parts. The potential of these vegetables to contribute to agro-biodiversity at farm (household) level through intercropping them with other crops also needs to be explored. In addition, the possibility of commercialising $\mathrm{WV}$ production and making them available to urban populations needs to be researched.

\section{Conclusions}

Wild vegetables have various roles in subsistence farming systems. They are a source of food and are particularly rich in micronutrients. They are consumed as relish to accompany 
the main cereal staple dish. They also contribute to dietary diversity and agro-biodiversity at the household level. Major threats to WV use include utilisation without cultivation and their elimination from cultivated fields as weed species which leads to the depletion of the natural population. Further research on various aspects of WV is needed. Peoples' attitudes and perceptions, the nutritional value of $\mathrm{WV}$, morphogenetic characterisation, plant improvement and agronomic research on soil fertility requirements and ability to be intercropped are some of the areas that require further investigation.

Acknowledgements Part of the funding for this study was provided by Stellenbosch University in the form of a merit bursary.

Conflict of interest The authors declare that they have no conflict of interest.

Open Access This article is distributed under the terms of the Creative Commons Attribution License which permits any use, distribution, and reproduction in any medium, provided the original author(s) and the source are credited.

\section{References}

Adebooye, O. C., \& Opabode, J. T. (2004). Status of conservation of the indigenous leaf vegetables and fruits of Africa. African Journal of Biotechnology, 3(120), 700-705.

Altman, M., Hart, T., \& Jacobs, P. (2009). Food security in South Africa. Centre for Poverty, Employment and Growth, Human Sciences Research Council. 29 pp.

Bharucha, Z., \& Pretty, J. (2010). The roles of wild foods in agricultural systems. Philosophical Transactions of the Royal Society B, 365, 2913-2926.

Bradford, J. (2010). The Food System and Resilience. Post-carbon Institute. www.postcarbon.org/article/62430-the-food-systemand-resilience. Accessed 23 September 2012.

Chambers, R. (1990). Rural Development: Putting the last first. Essex, Uk: Longman Scientific and Technical. 246 pp.

Devereux, S., \& Maxwell, S. (2001). Food security in sub-Saharan Africa. London: ITDG.

Faber, M., \& Wenhold, F. (2007). Nutrition in contemporary South Africa. Water $S A, 33(3), 393-400$. Special Edition.

FAO. (2008). An introduction to basic concepts of food security. Food Security Information for Action. Practical Guides. 3 pp. Food and Agricultural Organization Food Security Programme. www.fao.org/ docrep/013/a1936e/a1936e00.pdf. Accessed 23 March 2012.

Flyman, M. V., \& Afolayan, A. J. (2006a). A survey of plants used as wild vegetables in four districts of Botswana. Ecology of Food and Nutrition, 45, 405-415.

Flyman, M. V., \& Afolayan, A. J. (2006b). The suitability of wild vegetables for alleviating human dietary deficiencies. South African Journal of Botany, 72, 492-497.

Gupta, S., Lakshimi, A. J., \& Prakash, J. (2006). In vitro bioavailability of calcium and iron from selected green leafy vegetables. Journal of the Science of Food and Agriculture, 86, 2147-2152.

Harvestplus. (2011). What is hidden hunger? Breeding Crops for Better Nutrition. www.harvestplus.org/content/nutrients. Accessed 18/ $09 / 11$.

Hendriks, S. L. (2005). The challenges facing empirical estimation of food (in) security in South Africa. Development Southern Africa, 22(1), 103-123.
Jacobs, P. T. (2009). The status of household food security targets in South Africa. Agrekon, 48(4), 410-433.

Jansen van Rensburg, W. S., van Averbeke, W., Slabbert, R., Faber, M., van Jaarsveld, P., van Heerden, I., et al. (2007). African leafy vegetables in South Africa. Water SA, 33(3), 317-326.

Kepe, T. (2008). Social dynamics of the value of wild edible leaves (imfino) in a South African rural area. Ecology of Food and Nutrition, 4(6), 53-538.

Koch, J. (2011). The food security policy context in South Africa. International Policy Centre for Inclusive Growth, Country Study. United Nations Development Programme. 48 pp.

Kwapata, M.P., \& Maliro, M.F. (1995). Indigenous vegetables in Malawi: Germplasm collecting and Improvement of production practices. Paper presented at the workshop,"Genetic Resources of Traditional Vegetables in Africa. Options for Conservation and Use", 29 - 31 August 1995, Nairobi Kenya. http://www.bioversity international.org/publications. Accessed 18/09/11.

Legwaila, G. M., Mojeremane, W., Madisa, M. E., Mmolotsi, R. M., \& Rampart, M. (2011). Potential of traditional food plants in rural household food security in Botswana. Journal of Horticulture and Forestry, 3(36), 171-177.

Lewu, F. B., \& Mavengahama, S. (2010). Wild vegetables in northern KwaZulu-Natal, South Africa: Current status of production and research needs. Scientific Research and Essays, 5(20), 3044-3048.

Lewu, F. B., \& Mavengahama, S. (2011). Utilization of wild vegetables in four districts of northern KwaZulu-Natal province, South Africa. African Journal of Agricultural Research, 6(17), 4159-4165.

Lonnerdal, B. (2003). Genetically modified plants for improved trace element nutrition. Journal of Nutrition, 133, 1490S-1493S.

Maanda, M. Q., \& Bhat, R. B. (2010). Wild vegetable use by the VhaVenda in the Venda region of Limpopo Province, South Africa. International Journal of Experimental Botany, 79, 189194.

Maholtra, A., \& Passi, J. (2007). Diet, quality and nutritional status of rural adolescent girl beneficiaries of ICDS in north India. Asia Pacific Journal of Clinical Nutrition, 16, 8-16.

Maunder, E. M. W., \& Meaker, J. L. (2007). The current and potential contribution of home-grown vegetables to diets in South Africa. Water $S A, 33(3), 401-406$.

Maxwell, S., \& Smith, M. (undated). Household food security: A conceptual review, $72 \mathrm{pp}$. http://www.ifad.org/hfs/tools/hfs/ hfspub/hfs_1.pdf. Accessed 15 July 2012.

McLachlan, M., \& Garrett, J. (2008). Nutrition change strategies: the new frontier. Public Health Nutrition, 11(10), 1063-1075.

Michaelsen, K. F., Hoppe, C., Roos, N., Kaesel, P., Stougaard, M., Lauritzen, L., et al. (2009). Choice of foods for moderately malnourished children 6 months to 5 years of age. Food and Nutrition Bulletin, 30(3), S343-S404.

Mnzava, N. A. (1997). Vegetable crop diversification and the place of traditional species in the tropics. In L. Guarino (Ed.), Traditional African vegetables. Rome, Italy: International Plant Genetic Resources Institute.

Modi, M., Modi, A. T., \& Hendriks, S. (2006). Potential role for wild vegetables in household food security: A preliminary case study in KwaZulu-Natal, South Africa. African Journal of Food Agriculture Nutrition and Development, 6(1), 1-7.

Moore, C., \& Raymond, R. D. (2006). Back by popular demand: The benefits of traditional vegetables. International Plant Genetic Resources Institute (pp. 50). www.bioveristyinternational.org/fileadmin/bioversity/.../pdfs/1090.pdf. Accessed 18/09/11

Ndlovu, J., \& Afolayan, A. J. (2008). Nutritional analysis of the South African wild vegetable Corchorus olitorius L. Asian Journal of Plant Science, 7(6), 615-618.

Nesamvuni, C., Steyn, N. P., \& Potgieter, M. J. (2001). Nutritional value of wild, leafy vegetables consumed by the VhaVhenda. South African Journal of Science, 97, 51-54. 
Odhav, B., Beekrum, S., Akula, U., \& Baijnath, H. (2007). Preliminary assessment of nutritional value of traditional leafy vegetables in KwaZulu-Natal, South Africa. Journal of Food Composition and Analysis, 20, 430-435.

Oniang'o, R. K., Mutuku, J. M., \& Malaba, S. J. (2003). Contemporary African food habits and their nutritional and health implications. Asia Pacific Journal of Clinical Nutrition, 12, 331-336.

Rubaihayo, E.B. (2002). The contribution of indigenous vegetables to household food security. IK Notes 44 . World Bank. 4 pp. www.worldbank.org/ik/iknt44.pdf. Accessed 18/09/11.

Shackleton, C. M. (2003). The prevalence of use and value of wild edible herbs in South Africa. South African Journal of Science, 99, 23-25.

Shackleton, S., Twine, W., Hunter, L., Holding-Anyonge, C., \& Petheram, L. (2006). Forests as safety nets for mitigating the impacts of HIV/AIDS in southern Africa. Forest Livelihood Briefs, 4, 1-4.

Smith, F. I., \& Ezyaguirre, P. (2007). African leafy vegetables: Role in World Health Organization's Global Fruit and Vegetables Initiative. African Journal of Food Agriculture Nutrition and Development, 7(3), 1-17.

Steyn, N. P., Olivier, J., Winter, P., Burger, S., \& Nesamvuni, C. (2001). A survey of wild, green leafy vegetables and their potential in combating micronutrient deficiencies in rural populations. South African Journal of Science, 97, 276-278.

Tisdale, S. L., Nelson, W. L., \& Beaton, J. D. (1990). Soil fertility and fertilizers (4th ed.). New York. p: Macmillan Publishing Company. 754.

Uusiku, N. P., Oelofse, A., Duodu, K. G., Bester, M. J., \& Faber, M. (2010). Nutritional value of leafy vegetables of sub-Saharan Africa and their potential contribution to human health: a review. Journal of Food Composition and Analysis, 23(6), 499-509.

Venter, S. L., Jansen van Rensburg, W. S., Vorster, H. J., van den Heever, E., \& van Zijl, J. J. B. (2007). Promotion of African leafy vegetables within the agricultural research council - vegetable and ornamental plant institute: the impact of the project. African Journal of Food Agriculture Nutrition and Development, 7(4), 1-7.

Vorster, I. H. J., Jansen van Rensburg, W. S., \& Venter, S. L. (2007). The importance of traditional leafy vegetables in South Africa. African Journal of Food Agriculture Nutrition and Development, 7(4), 1-13.

Vorster, H. J., Stevens, J. B., \& Steyn, G. J. (2008). Production systems of traditional leafy vegetables: Challenges for research and extension. South African Journal of Agricultural Extension, 37, 85-96.

White, P. J., \& Broadly, M. R. (2009). Biofortification of crops with seven mineral elements often lacking in human diets - iron, zinc, copper, calcium, magnesium, selenium and iodine. New Phytologist, $182,49-84$

World Health Organization (WHO). (2000). World Health Report. Geneva: WHO.

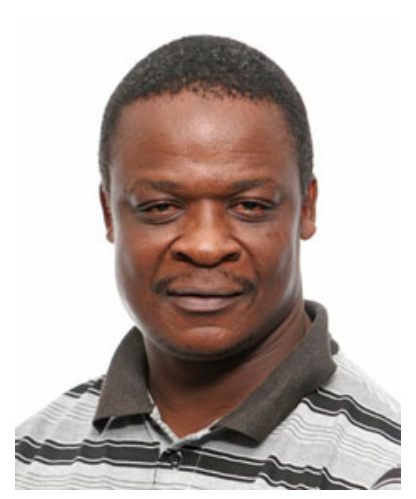

Sydney Mavengahama is a lecturer in the department of agronomy at the University of Zululand in South Africa and is also a $\mathrm{PhD}$ candidate at Stellenbosch University. $\mathrm{He}$ is a research agronomist with expertise in agronomy on-station and on-farm experimentation. His research interests are in soil fertility, integrated crop management, crop science and crop improvement. He is also interested in rural development issues to do with the development of smallholder agriculture.

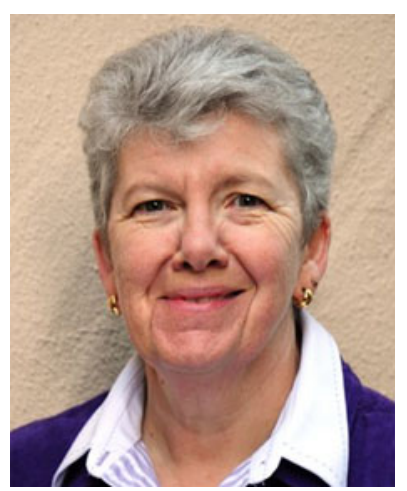

Milla McLachlan has been involved in international social development for more than 30 years, focusing on addressing food and nutrition issues though public policy, publicprivate partnerships and community action. Among other roles, she served as Principal Policy Analyst on poverty and social issues at the Development Bank of Southern Africa, and as Nutrition Advisor in the World Bank in Washington DC. Since her return to South Africa in 2006, Milla has consulted wide-

ly in Africa, building capacity for community-based action on nutrition, and facilitating leadership and partnership building activities. With a particular interest in social change as it relates to food systems, Milla now enjoys navigating the interface between research, policy and practice through her leadership and involvement in the SU Food Security Initiative (FSI), the Community Nutrition Security Project of the SU Division of Human Nutrition, and the Southern African Food Lab, a multi-stakeholder initiative using social innovation to shift the food system towards greater sustainability. Prof. McLachlan holds a $\mathrm{PhD}$ and MA from Michigan State University, and an MA in Transpersonal Psychology (Ecopsychology) from Naropa University. She has published several peer-reviewed journal articles, book chapters and reviews, and co-edited Combating Malnutrition: Time to Act, a World Bank publication on nutrition change strategies.

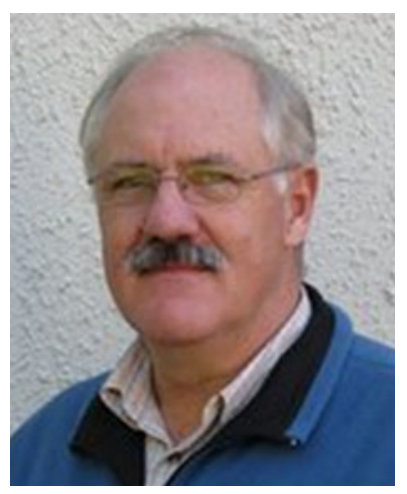

Willem de Clercq (PhD) has 25 years of experience in water and soil research. He coordinated a number of multi-disciplinary and multi-partner research projects. He worked on the development of criteria and management options for saline water irrigation, the development of a water quality information system, and the identification of factors influencing the water quality of rivers in South Africa. His current focal point is land use change in the dryland salinity region of the Western Cape and the effect this has on the water quality of the major rivers through the use of hydrological modelling. He further worked on tools for water managers to manage water quality and quantity for water management areas. This also led to mapping of salinity through remote methods.

Willem is also currently managing the Stellenbosch University's role in a FP7 research program involving 9 countries, focussing on more food production with less water in rural communities. Willem is also an active member of both ACCESS and SASSCALL research in South Africa (involving 6 countries), with principal focus, the climate change impact on water resources and agriculture through hydrological research.

During the past 12 years, Willem published more than 40 articles and participated in more than 40 conferences locally and internationally. Besides being involved with the Soil Science department, Willem is also a member of the Water Institute of Stellenbosch University. 